\title{
DIAMOND AND DLC LAYERS FOR A WIDE RANGE OF APLICATIONS
}

Summary: Diamond and diamond-like carbon (DLC) layers are nowadays of increasing importance for electrical and mechanical applications. In our laboratory we grow diamond on different substrates (Si, WC-Co) using Hot Filament Chemical Vapor Deposition (HF CVD) method improved by double biasing and DLC layers using pulsed arc system again on different substrates (Si, Ni, glass, Ti-6Al-4V, steel, WCCo). Growth parameters facilitate to control crystallinity of diamond layers from microcrystalline to nanocrystalline type. Mechanical, electrical and optical parameters are possible to change using doping with hydrogen, nitrogen, or oxygen. The goal of this article is to summarize recent results achieved in our laboratory related to applications of diamond and DLC layers for their use in sensors of hard metal in water and medical implantable joints.

\section{Introduction}

Carbon is the sixth most abundant element in the universe. In addition, carbon is a very special element because carbon is your body, food you eat, clothes you wear, cosmetics you use and gasoline that fuels your car. Carbon, discovered in prehistory was known to the ancients, who manufactured it by burning organic material for charcoal production. In Fig. 1 there are four popular allotropes of carbon: amorphous carbon, graphite, diamond and fullerene (nanotubes) [1].

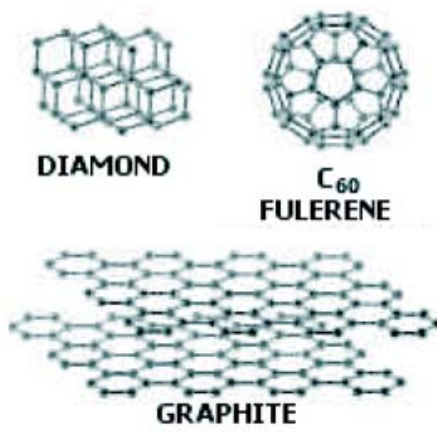

Fig. 1 Carbon Allotropes: Diamond, Buckminster fullerene, Carbon nanotube, and Graphite
Diamond and DLC have many excellent electrical, chemical, mechanical and biological properties [2]. Diamond is the hardest material known, it is extremely chemically inert and biologically compatible.

Electrical properties of diamond are: the highest electrical breakdown voltage, the highest thermal conductivity and the widest electromagnetic radiation transparency range of any material, as well as wide bandgap and high carrier mobilities. As an illustration of the excellent properties of diamond, Fig. 2 compares various wide-gap materials in terms of carrier mobility and thermal management properties, represented by surface area of the plotted circles. Recent progress in chemical vapor deposition (CVD) diamond technology has enabled the preparation of high-quality n-type CVD diamond layers using phosphorus as an n-type dopant and boron, nitrogen, hydrogen as p-type dopants. CVD diamond can therefore be considered as a new interesting conventional wide-gap semiconducting material having both n-type and p-type conductivity, which makes it attractive for numerous applications in high-temperature, high-voltage and high-frequency devices [3].

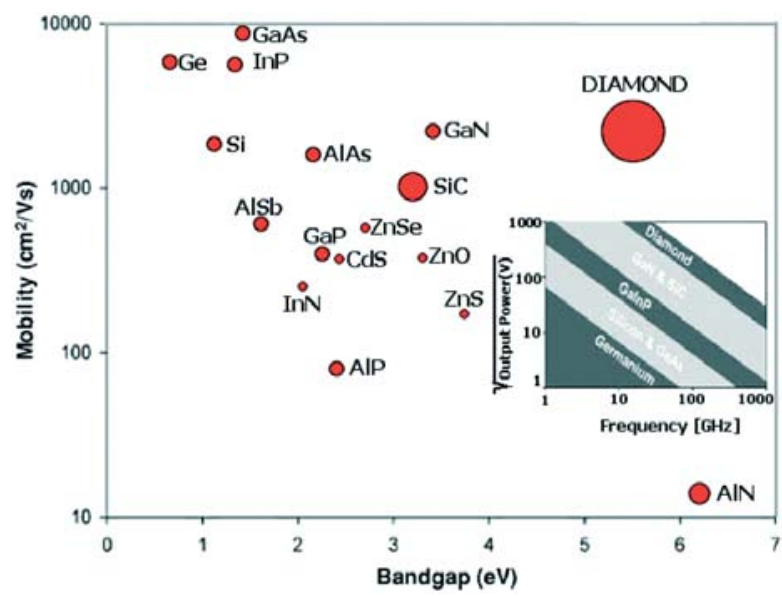

Fig. 2 Comparison of mobility materials together with thermal conductivity as represented by the surface area of the circles. The inset shows predicted performances, expressed as the square root of the output power, for high-frequency applications by using various semiconducting materials.

\footnotetext{
* M. Vojs, M. Veselý

Slovak University of Technology, Faculty of Electrical Engineering and Information Technology, Ilkovičova 3, 81219 Bratislava, Slovak Republic, Tel: +421 260291 366; E-mail: marian.vojs@stuba.sk
} 
The electrochemical approach is attractive because of sensitivity and dynamic range, portability and ease of application. Diamond and DLC is an attractive alternative electrode for electroanalysis on account of the reproducibility and chemical inertness, low background currents, and wide working potential window which this material exhibits in electrochemistry. One of the applications of diamond and DLC, carbon nitride $\mathrm{CN}_{\mathrm{x}}$, is for fast detection and determination of trace metals in solutions. Major importance lies in electrochemical analysis, where single or multiple heavy metals-containing systems are invariably encountered. Electrochemical stripping voltammetry methods offer a simple, quick and cheap way of detecting trace metals such as $(\mathrm{Pb}, \mathrm{Cu}, \mathrm{Cd}, \mathrm{Mn}, \mathrm{Ag})$ in water $[4,5]$

Biomaterials are an important aspect in the development of biomedical devices and implants and this area of research has been expanding rapidly over the last 50 years. It is the surface of a biomaterial which first contacts with the living tissue when biomaterial is placed in the body. Titanium alloy (Ti-6Al-4V) is well established as a primary metallic biomaterial for orthopedic implants. However, the host response to Ti-6Al-4V is not always favorable, whereby a fibrous layer may form at the skeletal tissue-device interface, resulting in implant failure. Therefore, there is a need to develop novel micro-engineered surfaces to provide better biological outcomes. DLC and carbon nitride $\mathrm{CN}_{\mathrm{x}}$ are excellent candidates for use as biocompatible coatings on biomedical implants, which are due to not only their excellent properties but also their chemical composition containing only carbon, hydrogen and nitrogen, which are biologically compatible elements [6].

\section{Experimental}

\section{Diamond deposition}

Deposition of polycrystalline diamond (PCD) over surface was carried out in the double bias enhanced HF CVD reactor described previously [7]. The gas phase was a mixture of $2 \% \mathrm{CH}_{4}$ in $\mathrm{H}_{2}$, the total pressure in the reactor was $3000 \mathrm{~Pa}$ and flow rates were $6: 300 \mathrm{sccm}$. Gases were activated by 5 tungsten filaments $0.7 \mathrm{~mm}$ thick, $120 \mathrm{~mm}$ long, heated to $2100{ }^{\circ} \mathrm{C}$. The substrate temperature was maintained at $750{ }^{\circ} \mathrm{C}$ (measured by a K-type thermocouple mounted in $80 \mathrm{~mm}$ a molybdenum substrate holder with filament-substrate distance of $10 \mathrm{~mm}$ ). The process of a PCD layer deposition was divided into three stages. The stage Nucleation was performed at negative substrate bias of $170 \mathrm{~V}$ for $30 \mathrm{~min}$ in $2 \%$ gas mixture. The stage Growth was enhanced only by dc plasma formed in the region between heated filaments and the above-situated grid (positive grid bias of $100 \mathrm{~V}$ with respect to filaments) in $2 \%$ gas mixture for $120 \mathrm{~min}$. The stage Termination, methane source was switched off, and for 180 min still termination process took place in $\mathrm{H}_{2}$ plasma onto polycrystalline diamond for change of electrical properties.

\section{DLC deposition}

DLCs were deposited in a UVNIPA-1-001 vacuum system with three sources (gas ion source for cleaning, electric arc source for non-magnetic metal sputtering and pulse arc carbon source for
DLC deposition). The pulse sputtering of graphite target is a possible setup in the range of $(f=1,2,3,5,10,15,20$ and $30 \mathrm{~Hz})$.

Samples entering were sputtered in one vacuum cycle. All of substrates (microelectrode arrays and medical hips) were cleaned for 10 min with Ar ions. After cleaning the hip was covered with $50 \mathrm{~nm}$ Ti interlayer for better adhesion of DLCs and for heated up bulk substrate to temperature about $200{ }^{\circ} \mathrm{C}$. For deposition of MEA (the technological process is described later) is this step missing, but a Ti interlayer is not needed. Consequently the DLC layer $\left(\sim 150{ }^{\circ} \mathrm{C}\right)$ was deposited at low deposition temperature. Nitrogen with $30 \mathrm{sccm}$ flow rate was added during the DLC deposition into a working chamber. The substrates were planetary rotating through all the deposition steps for homogeneous deposition.

\section{MicroElectrode Array}

Fig. 3 shows all the technological steps of manufacturing a $1 \times 1 \mathrm{~mm}$ microelectrode array (MEA) structure consisting of 50625 microdiscs with $3 \mu \mathrm{m}$ in diameter and distance of $20 \mu \mathrm{m}$ between microdiscs on Si with low resistivity $(0.008-0.024 \Omega \mathrm{cm})$.

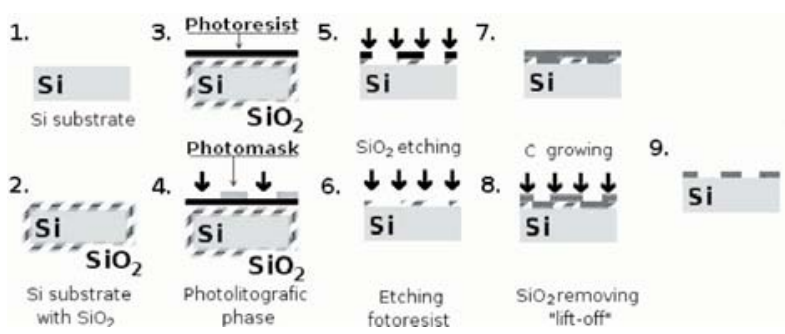

Fig. 3 Technological process of manufacturing a microelectrode array

The 1-st step was to clean the substrate in ultrasonic acetone bath. Then, the 2-nd step, about $300 \mathrm{~nm}$ thick $\mathrm{SiO}_{2}$ layer was created during 6 hours with the substrate at $1200{ }^{\circ} \mathrm{C}$ in dry $\mathrm{O}_{2}$ atmosphere in a furnace. During the standard photolithographic process, as steps 3 to 6, MEA structure in $\mathrm{SiO}_{2}$ layer was produced through a lithographic mask. After MEA preparation there are two ways for deposition of carbon layers (diamond or DLC), the 7-th step.

After PCD or $\mathrm{CN}_{\mathrm{x}}$ deposition the lift off technique is potentially used for $\mathrm{SiO}_{2}$ removal from the substrate. The overgrowen diamond or DLC layer is removed if necessary, the 8-th step. At this stage of the overall process we have a completely prepared MEA for electrochemical measurement, the 9-th step.

\section{Hip replacement joints}

Standard biocompatible alloy of Ti-6Al-4V supplied by prof. Zitnansky from the Faculty of Mechanical Engineering of the Slovak University of Technology in Bratislava was used as the substrate. The substrate face corresponds to special human hip replacement joints with the surface roughness after rough machining of about $R_{a}=10 \mu \mathrm{m}$, were $10 \mathrm{~min}$. rinsed in acetone in an ultrasonic bath and than washed in deionized water. 


\section{Results and discussion}

We can see in Fig. 4 SEM images of a deposited layer surface after the complete technological process. In Fig. 4 a) MEA polycrystalline diamond structure, in Fig. 4 b) $\mathrm{CN}_{\mathrm{x}}$ layer structure are displayed, both deposited on $\mathrm{Si}$. In case of polycrystalline diamond, the diamond layer was deposited on a freshly etched silicon surface. The areas which act as working electrodes (microdiscs) were defined photolithographically. Finally, the insulating resist mask layer was hardbaked to improve its adhesion. The behavior of a bare electrode array was characterized by cyclic voltammetry at the scan rate of $50 \mathrm{mV} / \mathrm{s}$ in $0.1 \mathrm{~mol} / 1 \mathrm{KNO}_{3}$ (acidified by $\mathrm{HNO}_{3}$ to $\mathrm{pH}$ 2.5). Differential pulse anodic stripping voltammetry was used for determination of $\mathrm{Pb}^{2+}$ ions in solution on bare $\mathrm{CN}_{\mathrm{x}}$ and polycrystalline electrodes. A preconcentration step was carried out at $-700 \mathrm{mV}$ vs $\mathrm{Ag} / \mathrm{AgCl} / \mathrm{Cl}^{-}$for $180 \mathrm{~s}$. Lead ions were co-deposited with $\mathrm{Hg}^{2+}$ ions $\left(1 \times 10^{-3} \mathrm{~mol} / \mathrm{l}\right)$ in $0.1 \mathrm{~mol} / 1 \mathrm{KNO}_{3}(\mathrm{pH} 2.5)$. All the experimental solutions were prepared from chemicals of analytical grade in $18 \times 10^{4} \Omega \mathrm{m}$ water.

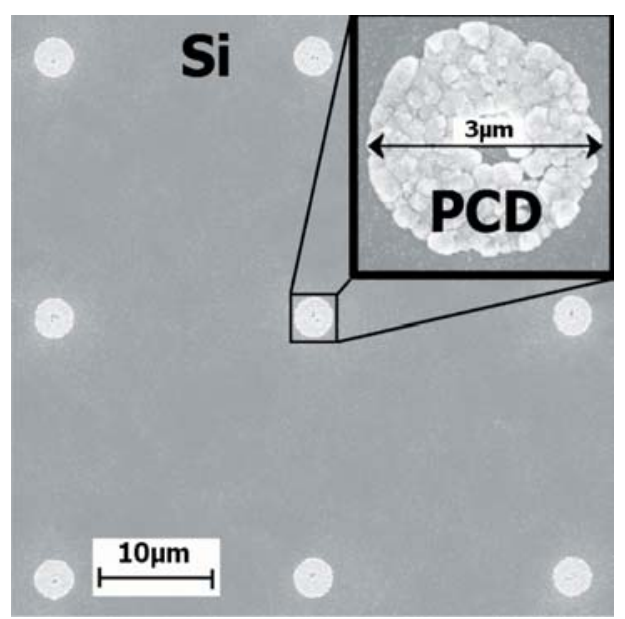

Fig. 4 a) SEM Image of polycrystalline diamond PCD microelectrode array

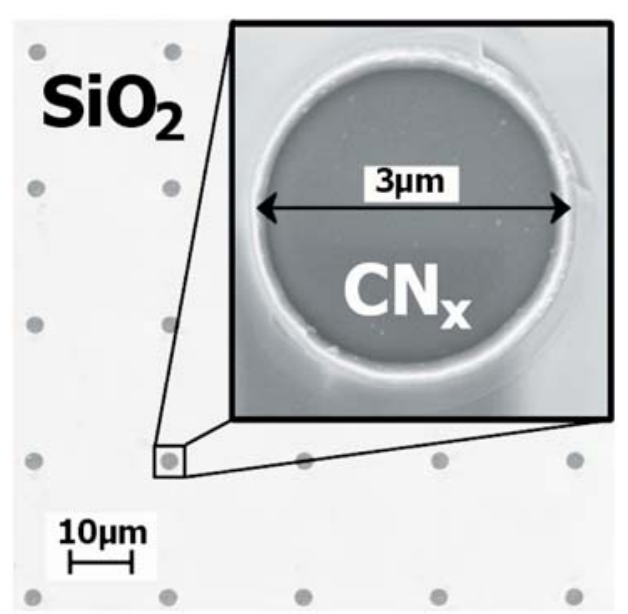

Fig. 4 b) SEM Image of carbon nitride CNx microelectrode array
$\mathrm{CN}_{\mathrm{x}}$ microelectrode array for in-situ determination of $\mathrm{Pb}^{2+}$ ions was prepared by co-deposition of $\mathrm{Pb}^{2+}$ at $-700 \mathrm{mV}$ vs. $\mathrm{Ag} / \mathrm{AgCl} / \mathrm{Cl}^{-}$in $0.1 \mathrm{~mol} / 1 \mathrm{KNO}_{3}$ with different content of $\mathrm{Pb}^{2+}$ for $180 \mathrm{~s}$ preconcentration time under constant magnetic striping. Stripping currents at $-566 \mathrm{mV}$ vs. $\mathrm{Ag} / \mathrm{AgCl} / \mathrm{Cl}^{-}$from reoxidation of $\mathrm{Pb}\left(\mathrm{Pb}^{0} \rightarrow \mathrm{Pb}^{2+}+2 \mathrm{e}\right)$ into the same solution were recorded by DP ASV. The minimum measurable current response to $\mathrm{Pb}^{2+}$ concentration on PCD was $1.10^{-4} \mathrm{~mol} / \mathrm{l}$, and on $\mathrm{CN}_{\mathrm{x}} 5 \times 10^{-6} \mathrm{~mol} / \mathrm{l}$.

The homogeneity of $\mathrm{CNx}$ layer was very high, it can be seen in Fig 5. DLC is in a dense, metastable form of amorphous carbon a-C, or hydrogenated amorphous carbon a-C:H containing a significant number of $\mathrm{sp}^{3}$ bonds. In other words, DLC consists of amorphous carbon and disordered graphite, and its atomic structure contains mixture of $\mathrm{sp}^{3}$ and $\mathrm{sp}^{2}$ sites. The $\pi$ state of $\mathrm{sp}^{2}$ controls the electrical properties and $\mathrm{sp}^{3}$ controls the mechanical properties. Experimentally obtained $\mathrm{CN}_{\mathrm{x}}$ films are composed of two phases that have $\mathrm{sp}^{3}$ and $\mathrm{sp}^{2}$ bonded structure [8]. Therefore, the concentration of nitrogen in the structure of $\mathrm{CN}_{\mathrm{x}}$ coatings is a key factor affecting the coating characteristics, up to now not yet studied.

\section{$10 \mathrm{~mm}$}

Fig. 5 Optical image of $C N x$ layer on hip replacement joints

\section{Conclusion}

We have demonstrated a very wide range of applications for polycrystalline diamond prepared by the unique HF CVD processing method and for $\mathrm{CN}_{\mathrm{x}}$ layer prepared by a pulse arc system.

In an electronic application such as microelectrode array for measurement of heavy metals in water there is a possibility to use an arc system for $\mathrm{CNx}$ deposition on a large area substrate with high homogeneity at very low temperature of about $150{ }^{\circ} \mathrm{C}$ opposite to $700{ }^{\circ} \mathrm{C}$ in $\mathrm{HF}$ CVD.

Low deposition temperature opens a new window for many cheaper applications in medicine such as cover layers of hip replacement joints, nails, or cover microscopic glass for research of DNA or any biological tissue growth.

\section{Acknowledgement}

The presented work was supported by the Scientific Grant Agency of the Ministry of Education of the Slovak Republic and Slovak Grant Agency, No. 1/2061/05, 1/0170/03 and by Science and Technology Assistance Agency under the contract, No. APVT20-034404 and APVT-20-050702/04. 


\section{References}

[1] HEIMANN, R. B., EVSVUKOV, S. E., KOGA, Y.: Carbon allotropes: a suggested classification scheme based on valence orbital hybridization, Carbon, Volume 35, Issues 10-11, 1997, pp. 1654-1658.

[2] VOJS, M., VESELY, M., REDHAMMER, R., JANIK, J., KADLECIKOVA, M., DANIS, T., MARTON, M., MICHALKA, M., SUTTA, P.: Double bias HF CVD multilayer diamond films on WC-Co cutting tools, Diamond \& Related Materials 14, 2005, pp. 613-616.

[3] NESLADEK, M.: Conventional n-type doping in diamond: state of the art and recent progress, Semicond. Sci. Technol. 20, 2005, R19-R27.

[4] FOORD, J. S., HAO, W., EATON, K.: Detection of heavy metals in multianalyte solutions using diamond electrodes, phys. stat. sol. (a) 202, No. 11, 2005, pp. 2116-2121.

[5] LIU, L. X., LIU, E.: Nitrogenated diamond-like carbon films for metal tracing, Surface \& Coatings Technology 198, 2005, pp. 189-193.

[6] CUI, F. Z., LI, U. D. J.: A review of investigations on biocompatibility of diamond-like carbon and carbon nitride films, Surface and Coatings Technology 131, 2000, pp. 481-487.

[7] MALCHER, V., MRSKA, A., KROMKA, A., SATKA, A., JANIK, J.: Current Applied Physics, 2, 2002, pp. 201-204.

[8] ROBERTSON, J.: Pure Appl. Chem. 66, 1994, pp. 1789-1796. 